\title{
Pengukuran dan Analisis High Frequency Current Transformer Pendeteksi Partial Discharge
}

\author{
Andi Junaidi' ${ }^{1}$ M. Imbarothur mowaviq ${ }^{2}$;ri Wahyu Oktaviana Putri ${ }^{3}$ \\ 1, 2, 3 Institut Teknologi PLN \\ ${ }^{1}$ andi.junaidi@itpln.ac.id \\ ${ }^{2}$ mowaviq@itpln.ac.id \\ ${ }^{3}$ triwahyu@itpln.ac.id
}

\begin{abstract}
The lifetime of high voltage equipment is very dependent on the condition of insulation, poor insulation means the life span of high voltage equipment is getting shorter. Partial Discharge is one of the causes of deterioration of high voltage equipment insulation. The ability to know the phenomenon of partial discharge in equipment becomes very important and adds value to the maintenance of high voltage equipment. Many explanations regarding partial discharge, partial discharge is the lack of uniformity of the electric field in the isolation or dielectric media which will result in the phenomenon of Partial Discharge where this will lead to the failure of the isolation media. Partial Discharge that occurs continuously can cause damage (breakdown) on a high voltage equipment. Therefore, before a high voltage device is used, Partial Discharge detection is necessary. Partial Discharge Detection can use the Partial Discharge measurement circuit. In testing partial discharges can be tested using a sensor with various circuits including High Frequency Current Transformers (HFCT) so that this research will discuss one part of the Partial Discharge measurement circuit, the HFCT detector. Hopefully, the HFCT detector can be further developed and can be used for better partial discharge detection.
\end{abstract}

Keywords: Partial Discharge, High Voltage, HFCT

\begin{abstract}
ABSTRAK
Masa hidup peralatan tegangan tinggi sangat bergantung pada kondisi isolasinya, isolasi buruk artinya masa hidup peralatan tegangan tinggi menjadi semakin pendek. Partial Discharge merupakan salah satu penyebab deteriorasi isolasi peralatan tegangan tinggi. Kemampuan untuk mengetahui fenomena partial discharge dalam peralatan menjadi sangat penting dan memberikan nilai tambah pada pemeliharaan peralatan tegangan tinggi. Banyak penjelasan mengenai partial discharge, partial discharge merupakan ketidak-seragaman medan listrik dalam media isolasi atau dielektrik yang akan mengakibatkan terjadinya fenomena Partial Discharge dimana hal ini akan berujung pada kegagalan media isolasi tersebut. Partial Discharge yang terjadi terus menerus dapat menyebabkan kerusakan (breakdown) pada suatu peralatan tegangan tinggi. Oleh karena itu, sebelum suatu perlatan tegangan tinggi digunakan, perlu adanya deteksi Partial Discharge. Deteksi Partial Discharge ini dapat menggunakan rangkaian pengukuran Partial Discharge. Dalam pengujiannya partial discharge dapat diuji menggunakan sebuah sensor dengan berbagai rangkaian diantaranya rangkaian High frequency current transformer (HFCT) sehingga, pada penelitian ini akan dibahas salah satu bagian dari rangkaian pengukuran Partial Discharge, yaitu HFCT detector. Dengan harapan, HFCT detector dapat dikembangkan lebih jauh dan dapat digunakan untuk deteksi partial discharge lebih baik.
\end{abstract}

Kata kunci: Partial Discharge, Tegangan Tinggi, HFCT 


\section{KILAT}

Vol. 10, No. 1, April 2021, P-ISSN 2089-1245, E-ISSN 2655-4925

DOI: https://doi.org/10.33322/kilat.v10i1.983

\section{PENDAHULUAN}

Sistem isolasi modern diperlukan pada peralatan tegangan tinggi untuk meningkatkan umur pemakaian dari bahan isolasi yang terkena medan listrik yang tinggi. Banyaknya penggunaan konverter daya menyebabkan gelombang harmonik, gangguan frekuensi tinggi ini berada dan tersebar di kabel listrik. Gelombang harmonik menghasilkan tegangan lebih, yang dapat mempercepat penuaan isolasi dan meningkatkan resiko partial discharge[1].

Saat ini, beberapa teknik pengukuran PD online telah ditingkatkan dan diterapkan pada kabel listrik, dan aksesoris kabel seperti sambungan kabel dan terminasi[2]. Di antara metode tersebut, transformator arus frekuensi tinggi Sensor (HFCT) dengan teknik time domain reflectometry (TDR) biasanya digunakan untuk deteksi dan lokalisasi Sumber PD di kabel listrik. Selain itu, sensor HFCT efektif dalam kisaran $3 \mathrm{MHz}$ hingga $30 \mathrm{MHz}$ [3]. Namun, gangguan noise yang mempengaruhi pengukuran PD saat menggunakan sensor HFCT.

Deteksi PD dengan metode elektromagnetik, terdapat dua metode yakni metode konvensional yang berbasis di IEC standar 60270, di mana pulsa PD diukur dalam rentang frekuensi di bawah 1 $\mathrm{MHz}$ dan metode non-konvensional yang berbasis pada penggunaan sensor pengukur dengan rentang frekuensi di HF (3-30 MHz), VHF (30-300 MHz) dan UHF (300 MHz-3 GHz)[4]. Spesifikasi teknis baru (IEC 62478) yang juga mencakup metode listrik non-konvensional di samping teknik akustik saat ini sedang dipertimbangkan. Pada masa lalu Partial discharge telah dianalisis dengan membandingkan discharge amplitudo, dan waktu antara beberapa pulsa, beberapa penelitian telah menemukan pola umum untuk beberapa jenis kerusakan akibat partial discharge termasuk corona pada permukaan peralatan dan pelepasan muatan isolasi pada void[5]-[7]

Partial Discharge (PD) menyebabkan kerusakan progresif dari bahan isolasi, efek PD pada kabel tegangan tinggi dan peralatan bisa menyebabkan kegagalan isolasi[8]. Efek komulatif dari PD dalam isolasi padat adalah terjadinya proses pemohonan, peristiwa PD yang berulang menyebabkan kerusakan mekanik dan kimia ireversibel dari bahan isolasi. Transformasi kimia dielektrik juga cenderung meningkatkan konduktivitas listrik dari bahan dielektrik, hal ini meningkatkan stres listrik sehingga mempercepat proses kerusakan. Dalam kabel tegangan tinggi dengan isolasi kertas, partial discharge dimulai dengan adanya void (lubang-lubang) kecil yang menembus gulungan kertas yang berdekatan dengan konduktor listrik atau selubung luar.

Banyak metode yang dapat dilakukan untuk mendeteksi adanya PD pada isolasi, salah satunya adalah deteksi PD menggunakan metode non konvensional menggunakan sensor HFCT untuk mendeteksi PD pada kabel. Hingga saat ini, aplikasi yang paling praktis dalam metode pengukuran PD pada tegangan menengah (MV) kabel jaringan hampir secara eksklusif dilakukan off-line[9]. Selain itu sebagian besar sistem pengujian hanya menguji frekuensi rendah dari partial discharge [10].

Dalam penelitian ini, hasil perencanaan desain HFCT untuk sensor partial discharge sebagai bagian penelitian yang di deteksi dari pengukuran gelombang elektromagnetik yang disebabkan oleh PD. Pertama, dilakukan simulasi untuk menentukan karakteristik perencanaan. Kemudian, untuk menemukan unjuk kinerja HFCT, dilakukan analisa terhadap parameter-parameter dari HFCT. Kemudian dari hasil simulasi, dirancang high frequency current transformer tersebut. Dengan kata lain, uji partial discharge untuk deteksi cacat isolasi kabel tegangan tinggi oleh HFCT ini akan menjadi percobaan untuk melihat unjuk kerja HFCT yang telah dirancang.

\section{METODE/PERANCANGAN PENELITIAN}

\subsection{Metode UHF (Ultra High Frequency)}

Sebuah bagian dari HFCT dapat dimodelkan oleh rangkaian ekuivalen self capacitance modelling seperti yang ditunjukkan pada Gambar 3, di mana RL, LL, dan CS adalah sama dengan 
resistansi, induktansi, dan kapasitansi masing-masing. RL terutama disebabkan oleh lilitan dan rugirugi inti, dan CS menggambarkan peralihan terdistribusi efek kapasitansi parasit dari gulungan. Dalam Gambar 1, efek dari tanah pada kapasitansi induktor diabaikan. Akibatnya, model ini hanya cocok untuk kasus-kasus di mana tidak ada ground conductor di dekatnya, atau kapasitansi kumparan ke tanah diabaikan[4].

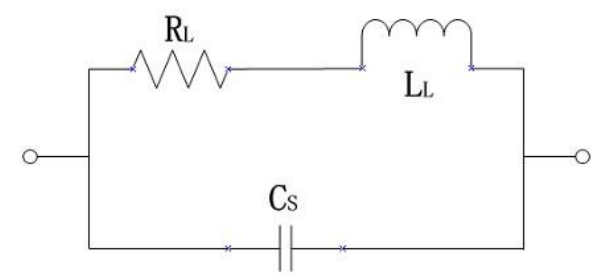

Gambar 1. Rangkaian ekivalen model HFCT

Alat ukur partial discharge terdiri atas Peralatan Pendeteksi (Sensor), Sistem Pengukuran, Sistem Pengolahan Sinyal, dan Sistem Penilaian. Lingkup proposal ini adalah integrasi dari keseluruhan sistem, sehingga seluruh aspek dapat terhubung dan bekerja sesuai fungsi masingmasing.

Konsep utama dari penelitian ini adalah sebuah sistem pengukuran portabel yang mampu merekam sinyal partial discharge, kemudian sinyal tersebut dapat diolah dan melalui sistem penilaian mampu mendiagnosa karakteristik partial discharge yang timbul. HFCT berfungsi untuk mengukur mengukur gelombang elektromagnetik yang disebabkan oleh PD secara langsung berdasarkan munculnya arus bocor dari fenomena partial discharge.

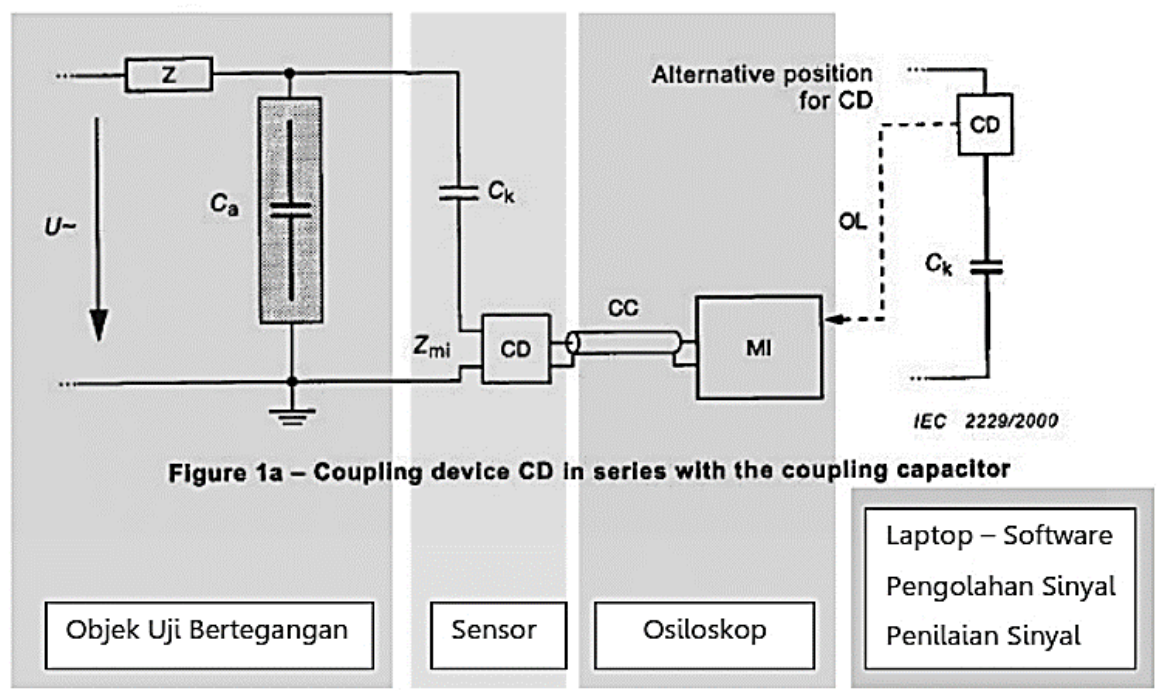

Gambar 2. Rangkaian Uji PD IEC 60270[11]

\section{HASIL DAN PEMBAHASAN}

\subsection{Hasil Pengujian HFCT}

Pada umumnya, HFCT bekerja pada rentang frekuensi tinggi/HF (3-30 MHz), tapi hasil desain yang penulis laksanakan HFCT ini dapat bekerja sampai rentang frekuensi GHz dimana merupakan rentang frekuensi UHF. Berdasarkan data hasil pengujian Tabel 4.1 hasil desain HFCT 1 mampu melakukan pengukuran sampai rentang frekuensi $7,005 \mathrm{GHz}$ dimana sensor tersebut mempunyai bandwith $\pm 500 \mathrm{Mhz}$. Sedangkan HFCT 2 mampu melakukan pengukuran sampai rentang frekuensi $2,5387 \mathrm{GHz}$ dan bandwith $\pm 200 \mathrm{MHz}$. 


\section{KILAT}

Vol. 10, No. 1, April 2021, P-ISSN 2089-1245, E-ISSN 2655-4925

DOI: https://doi.org/10.33322/kilat.v10i1.983

Kinerja dan daya guna suatu sensor HFCT dapat dilihat dari nilai parameter- parameter sensor tersebut. Beberapa dari parameter tersebut saling berhubungan satu sama lain. Parameter-parameter tersebut antara lain adalah impedansi masukan, voltage wave standing ratio (VSWR), return loss, bandwith, keterarahan serta penguatan. Hasil uji HFCT 1 mempunyai return loss dibawah -9,54 $\mathrm{dB}$ dan VSWR 1,235. Sedangkan HFCT 2 mempunyai return loss yang lebih besar $-10,36 \mathrm{~dB}$ dan VSWR 2,31.

Tabel 1. Hasil pengujian HFCT

\begin{tabular}{|c|c|c|c|c|}
\hline $\begin{array}{l}\text { Design } \\
\text { HFCT }\end{array}$ & $\begin{array}{c}\text { Measurement } \\
\text { Point }\end{array}$ & $\begin{array}{c}\text { Frequency } \\
(\mathbf{G H z})\end{array}$ & dB & Witdband \\
\hline \multirow[t]{4}{*}{ HFCT 1} & 1 & 2,7092 & $-9,642$ & $500 \mathrm{MHz}$ \\
\hline & 2 & 2,9128 & $-9,628$ & \\
\hline & 3 & 3,1328 & $-21,315$ & \\
\hline & 4 & 7,0005 & $-9,037$ & \\
\hline \multirow[t]{5}{*}{ HFCT 2} & 1 & 0,3018 & $-13,502$ & $200 \mathrm{MHz}$ \\
\hline & 2 & 1,2715 & $-12,183$ & \\
\hline & 3 & 2,2975 & $-9,6523$ & \\
\hline & 4 & 2,4301 & $-18,938$ & \\
\hline & 5 & 2,5387 & $-9,9004$ & \\
\hline
\end{tabular}

Analisa yang dilakukan dengan circuit analyzer tersebut memiliki kekurangan karena tidak mampu memperlihatkan kinerja HFCT pada rentang frekuensi yang lebih rendah. Hal ini disebabkan karena rangkaian tersebut tidak bisa di kalibrasi dan pengukuran yang dilakukan untuk menguji kinerja sensor hanya dilakukan pada rentang frekuensi $500 \mathrm{MHz}$ sampai $10 \mathrm{GHz}$.

\subsection{Pengukuran PD Menggunakan Sensor HFCT}

Dalam rangka untuk menganalisis unjuk kinerja dari HFCT yang telah di desain, maka dilakukan uji diagnosis PD. Diagnosis PD dilakukan pada elektroda dengan media isolasi minyak.

\subsubsection{Pembangkitan Sumber PD}

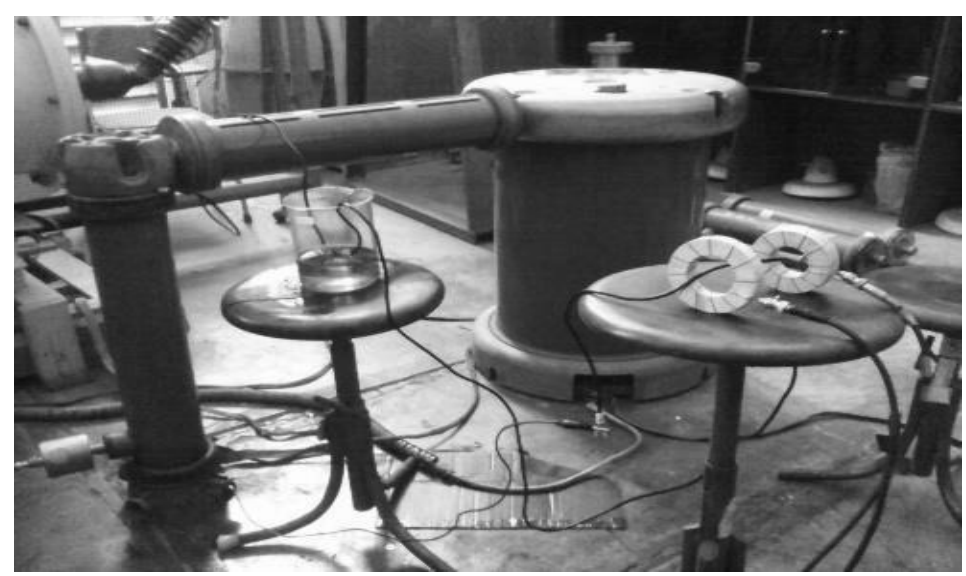

Gambar 3. Pembangkitan sumber PD

Sumber PD yang akan dibangkitkan adalah berupa PD tipe corona. PD ini dihasilkan oleh adanya perbedaan medan yang tinggi pada elektroda jarum plat yang digunakan. Bahan isolasi yang 
digunakan adalah minyak. Medan Listrik tinggi dihasilkan dengan menggunakan sistem elektroda jarum-plat dengan gap sebesar $10 \mathrm{~mm}$ antara dua elektroda tersebut. Elektroda jarum dengan panjang $5 \mathrm{~cm}$ dan diameter $1 \mathrm{~mm}$. Bagian ujung bersudut $30^{\circ}$ dan radius dari ujung jarum adalah $3 \mu \mathrm{m}$. Dengan geometri ini, medan listrik yang cukup kuat dapat diperoleh untuk menghasilkan discharge pada ujung jarum.

\subsubsection{Proses Pengukuran}

Partial Discharge tergantung pada tegangan sumber yang diberikan. Hasil investigasi intensif dari PD menunjukkan bahwa magnitude dan waktu dari tegangan sumber sangat berpengaruh terhadap karakteristik PD pada sistem isolasi. Sumber tegangan tinggi berasal dari trafo tegangan tinggi dengan arus yang kecil.

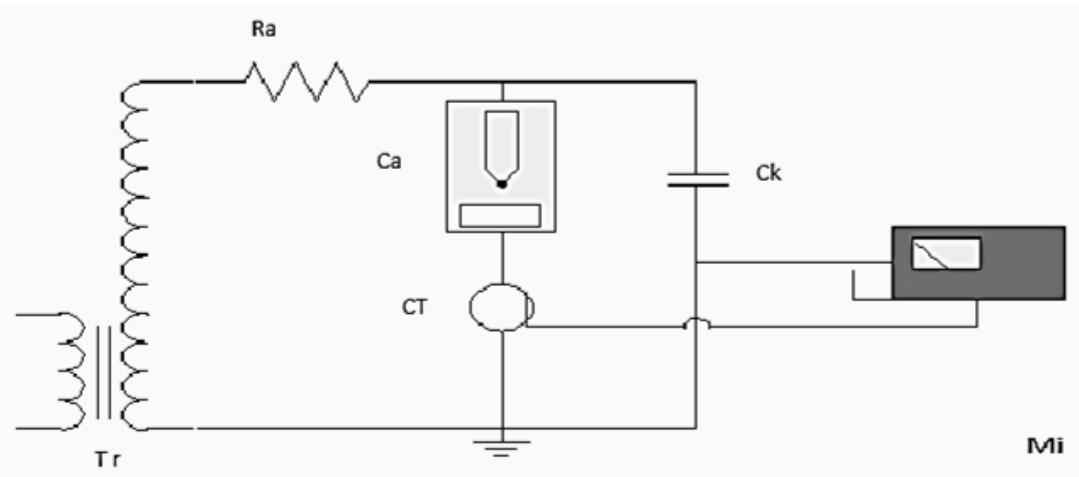

Gambar 4. Rangkaian Pengujian

Trafo step up buatan Mewandler type LT ini mempunyai rasio perbandingan sebesar $220 \mathrm{~V}$ : $100000 \mathrm{~V}$. Secara langsung, pengukuran parameter-parameter tegangan tinggi sangat sulit untuk dilakukan karena alat ukur yang digunakan tidak mampu untuk membacanya. Maka dari itu, harus digunakan voltage divider. Voltage divider ini berfungsi untuk membagi tegangan supaya tegangan keluaran bisa dibaca oleh alat ukur.

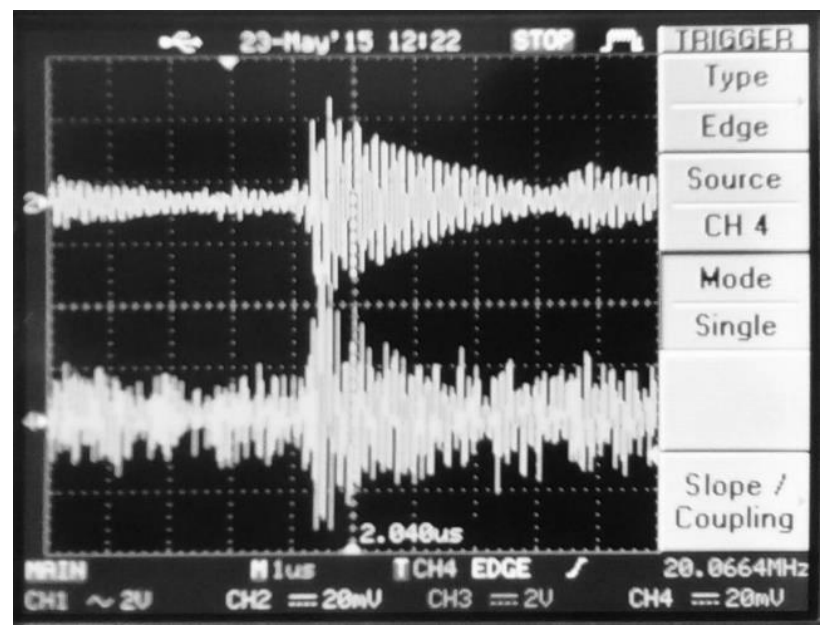

Gambar 5. Sinyal PD yang dideteksi oleh HFCT

Gambar 3.3 merupakan proses pengukuran PD yang dilakukan. HFCT ditempatkan setelah elektroda jarum plat, hasil pengukuran dibaca langsung oleh osiloskop. Hasil pengujian PD 


\section{KILAT}

Vol. 10, No. 1, April 2021, P-ISSN 2089-1245, E-ISSN 2655-4925

DOI: https://doi.org/10.33322/kilat.v10i1.983

menggunakan sensor HFCT menunjukkan sinyal PD yang dibaca oleh kedua sensor, Gambar 3.3 memperlihatkan sinyal PD yang berhasil ditangkap oleh masing-masing sensor mempunyai bentuk yang berbeda. Hasil pembacaan yang didapatkan oleh sensor HFCT 1 (ch. 2) menunjukkan sinyal PD mampu ditangkap sempurna oleh sensor tersebut.

\section{KESIMPULAN DAN SARAN}

Pada tulisan ini menjelaskan teori dan implementasinya dalam mendesain sebuah sensor partial discharge pada frekuensi yang tinggi. HFCT merupakan salah satu cara untuk mendeteksi keberadaan discharge pada isolasi. Untuk mengukur kinerja dari sebuah alat ukur discharge, yaitu sensor HFCT yang didesain adalah dengan melihat parameter- parameter sensor tersebut dan membandingkannya dengan standar yang ditetapkan. HFCT 1 dan HFCT 2 didesain dengan nilai parameter yang berbeda, ukuran inti yang berbeda sehingga didapatkan sebuah alat ukur sensor HFCT dengan karakteristik yang juga berbeda. HFCT 1 berdasarkan nilai parameternya mempunyai unjuk kinerja yang lebih baik bila dibandingkan dengan HFCT 2.

Selain itu kedua sensor tersebut juga mempunyai rentang frekuensi yang berbeda $(\mathrm{GHz})$ bila dibandingkan HFCT pada umumnya yang bekerja pada rentang frekuensi tinggi/HF (3-30 MHz). Hasil desain HFCT 1 mampu melakukan pengukuran sampai rentang frekuensi 7,005 GHz dimana sensor tersebut mempunyai bandwith \pm 500 Mhz. Sedangkan HFCT 2 mampu melakukan pengukuran sampai rentang frekuensi $2,5387 \mathrm{GHz}$ dan bandwith $\pm 200 \mathrm{MHz}$. Beberapa faktor yang mempengaruhi sensitifitas dari sebuah sensor HFCT diantaranya adalah jenis dan ukuran inti ferit, dan jumlah lilitan.

\section{UCAPAN TERIMAKASIH}

Penulis Mengucapkan terimaksih kepada Institut Teknologi-PLN yang telah memberi dukungan atas terlaksananya penelitian ini.

\section{DAFTAR PUSTAKA}

[1] Y. Ye, D. Liang, J. Du, M. Tang, X. Liu, and P. Equipment, "Design and Optimization of High Frequency Current Transformer," pp. 963-966, 2014.

[2] B. Zheng, W. Wang, C. Li, C. Li, and L. Zhang, "PD Detection of XLPE Cables Accessories on UHF," pp. 438-440, 2005.

[3] F. Álvarez, F. Garnacho, J. Ortego, and M. Á. Sánchez-urán, “Application of HFCT and UHF Sensors in On-Line Partial Discharge Measurements for Insulation Diagnosis of High Voltage Equipment," pp. 7360-7387, 2015, doi: 10.3390/s150407360.

[4] M. Haddad, "Advances in High Voltage Engineering ! DVANCES IN ( IGH."

[5] T. Klueter, J. Wulff, and F. Jenau, "Measurement and Statistical Analysis of Partial Discharges at DC Voltage," vol. 0, pp. 2-6.

[6] E. Corr, W. H. Siew, and W. Zhao, "Long Term Testing and Analysis of Dielectric Samples Under DC Excitation," no. June, pp. 19-22, 2016.

[7] X. Cable, L. Using, and D. C. Voltage, "Location of Water Tree Degraded Point Along," pp. $2-5,2008$.

[8] Y. Weens, N. Idir, R. Bausière, and J. J. Franchaud, "Modeling and Simulation of Unshielded and Shielded Energy Cables in Frequency and Time Domains," vol. 42, no. 7, pp. 1876-1882, 2006.

[9] S. M. Gargari, P. A. A. F. Wouters, P. C. J. M. Van Der Wielen, and E. F. Steennis, "Partial discharge parameters to evaluate the insulation condition of on-line located defects in medium 
voltage cable networks," IEEE Trans. Dielectr. Electr. Insul., vol. 18, no. 3, pp. 868-877, 2011, doi: 10.1109/TDEI.2011.5931076.

[10] E. F. Steennis, W. Boone, and D. Power, "Partial discharge diagnostics of long and branched medium-voltage cables," pp. 27-30, 2001.

[11] T. English-language, "INTERNATIONAL STANDARD," Int. Stand. IEC 60270, vol. 2000, 2000. 